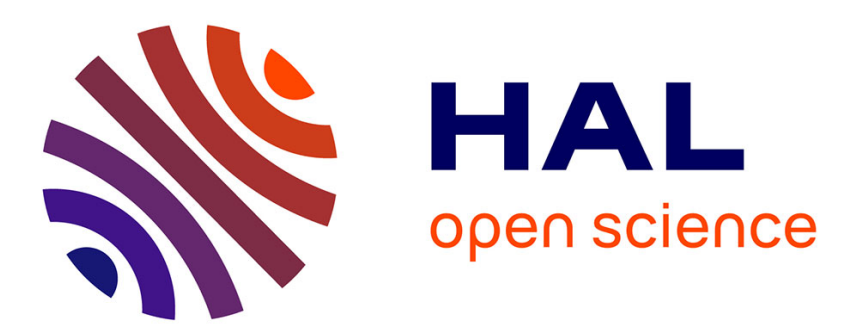

\title{
Basic study of plasma plume for film deposition by reactive laser ablation
}

\author{
J. Hermann, A.-L. Thomann, C. Boulmer-Leborgne
}

\section{To cite this version:}

J. Hermann, A.-L. Thomann, C. Boulmer-Leborgne. Basic study of plasma plume for film deposition by reactive laser ablation. Journal de Physique IV Proceedings, 1994, 04 (C4), pp.C4-123-C4-126. 10.1051/jp4:1994426 . jpa-00252689

\section{HAL Id: jpa-00252689 https://hal.science/jpa-00252689}

Submitted on 1 Jan 1994

HAL is a multi-disciplinary open access archive for the deposit and dissemination of scientific research documents, whether they are published or not. The documents may come from teaching and research institutions in France or abroad, or from public or private research centers.
L'archive ouverte pluridisciplinaire HAL, est destinée au dépôt et à la diffusion de documents scientifiques de niveau recherche, publiés ou non, émanant des établissements d'enseignement et de recherche français ou étrangers, des laboratoires publics ou privés. 


\title{
Basic study of plasma plume for film deposition by reactive laser ablation
}

\author{
J. HERMANN, A.-L. THOMANN and C. BOULMER-LEBORGNE
}

GREMI, Orléans University, CNRS, BP. 6759, 45067 Orléans cedex 2, France

\section{Introduction}

Thin layer deposition of TiN can be achieved by laser ablation of titanium in nitrogen or nitrogen containing atmospheres 1,2 . To optimise layer qualities, -i.e. homogeneity, roughness , an understanding of the laser vaporisation process is necessary. Therefore, we performed time- and space- resolved emission spectroscopy diagnostics of the vapour plasma formed in front of the Ti-target. In this paper, we present some results characterising the laser induced plasma and its propagation.

\section{Experimental set-up}

Irradiations are performed by an excimer laser (Questek model 2520Vß) operating with an $\mathrm{XeCl}$ active gas mixture and delivering pulses of $20 \mathrm{~ns}$ duration and variable energy $(\leq 400 \mathrm{~mJ})$. The repetition frequency is $8 \mathrm{~Hz}$. The laser beam is focused with the aid of a quartz lens of $500 \mathrm{~mm}$ focal length to a spot of roughly $1 \mathrm{~mm}^{2}$ and directed onto the targets surface with a $45^{\circ}$ angle. The Ti-target of $10 \mathrm{~mm} \times 10 \mathrm{~mm}$ area and $1 \mathrm{~mm}$ thickness is rotated with a $1 \mathrm{~Hz}$ frequency to avoid drilling. It is placed in a vacuum chamber which is evacuated up to $10^{-5}$ Torr between two measurement series. It is filled with nitrogen of low pressure $\left(10^{-2}\right.$ Torr...1Torr) during laser ablation measurements. Plasma observations are performed perpendicularly to the symmetry axis of vapour ejection (parallel to the targets surface). Two quartz lens of $200 \mathrm{~mm}$ focal length in a telescope configuration are used to project the plasma image on the entrance slit of an optical fibre. Hence, successive plasma layers of $0.1 \mathrm{~mm}$ thickness can be observed. The observation distance from the targets surface is varied by displacing the optical fibre ending with the aid of a mechanical displacement. The plasma emission light is analysed by a $2 \mathrm{~m}$ spectrometer. A fast photomultiplier coupled to a $400 \mathrm{MHz}$ digitizer allows for time resolved recordings. Digitizer and spectrometer are programmed by a microcomputer.

\section{Results}

The first step of plasma characterisation is the identification of the light emitting species. The analyse of the spectrum from $250 \mathrm{~nm}$ to $700 \mathrm{~nm}$ shows, that spectral line emission comes only from neutral and ionised species of the metal vapour, while the ambient gas keeps unexcited. For laser fluencies from 5 


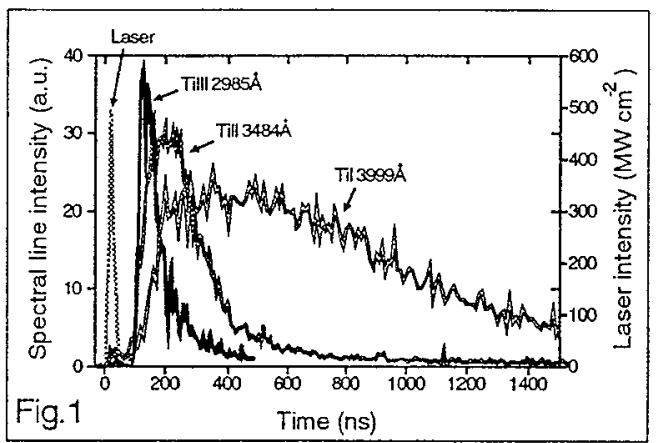

to $10 \mathrm{Jcm}^{-2}$ we could detect TiI, Till, Till, but not TiIV. Fig. 1 shows spectral line emission of these species as a function of time. The observation distance from target is $2 \mathrm{~mm}$. The laser temporal shape is also represented. The laser fluency is $10 \mathrm{Jcm}^{-2}$ and the pressure of ambient nitrogen is 1Torr. We note, that the emission from Till and Till starts nearly simultaneously, while the rising front of Til emission is delayed by some tenth of nanoseconds. We deduce that the vapour ejected from the metal surface contains primary TiIl and Tilll ions and that TiI is formed afterwards by recombination. An important result is the absence of emission from molecular or atomic nitrogen. On the first view, this is quite surprising because the ionisation level of Till $(13.6 \mathrm{eV})$ and is higher then the energies necessary for dissociation of $\mathrm{N}_{2}(9.8 \mathrm{eV})$ or for excitation of molecular $(6.2 \mathrm{eV})$ or atomic nitrogen. We can explain this by the fact that Till and Tilll are formed on the targets surface, where the laser beam is partly absorbed due to the high electron density. During its expansion into the ambient gas, the plasma temperature cools rapidly and dissociation or excitation of $\mathrm{N}_{2}$ by electron collisions becomes impossible. Fig. 2 shows the spectral line kinetics of the

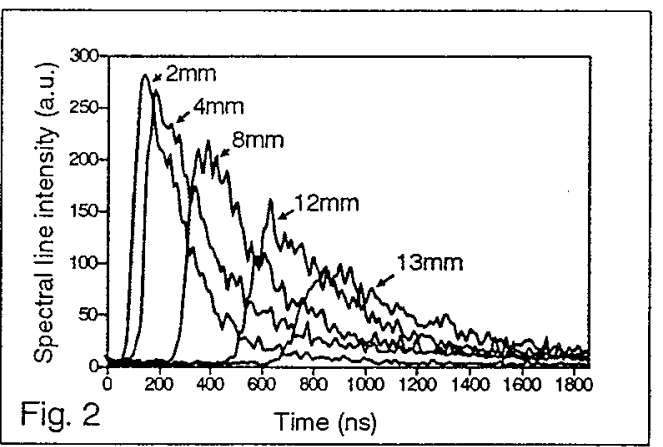

Till $3484 \AA$ line for $10 \mathrm{Jcm}^{-2}$ laser fluency and 1 Torr ambient nitrogen pressure at different observation distances from the targets surface. We note, that spectral line emission from Till can be observed up to a distance of roughly $20 \mathrm{~mm}$. TillI is detected only up to $3 \mathrm{~mm}$ while TiI is observable at distances even higher than $20 \mathrm{~mm}$.

Complementary information on the recombining vapour is obtained by recording spectral line profiles of neutral atoms or ions. We analysed line profiles of TiII and TiIII to determine the electron density from Stark broadening and shifting. Parameter of Stark broadening and shifting were known from previous experiments, where a titanium target was irradiated by a pulsed $\mathrm{CO}_{2}$ laser in an $\mathrm{He}$ atmosphere ${ }^{3}$. With respect to the UV excimer laser, the far infrared radiation from the $\mathrm{CO}_{2}$ laser heats efficiently the electrons due to inverse Bremsstrahlung and excitation or ionisation of the ambient He occurs for laser intensities of the order of $100 \mathrm{MWcm}^{-2}$ (Ref.4). We deduced spectral line broadening and shift parameters of several titanium lines of TiI, TiII, TiII, TiIV by comparing its width and shift with those of $\mathrm{He}$ lines having well known Stark broadening and shift parameters. 
To get the time evolution of electron density we recorded spectral line profiles as a function of time by the following way: The time evolution of light emission from a given plasma layer is recorded by the digitizer and transferred to the micro-computer for successive wavelengths selected by the spectrometer. The acquired data array of typically $500 \times 200$ data contains the time evolution of the selected spectrum.

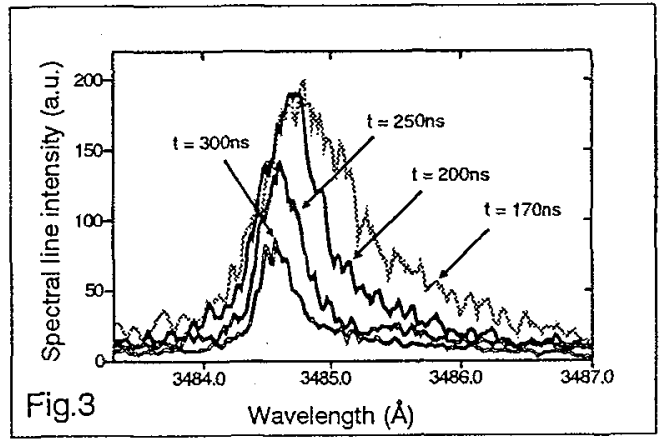

An example of such a recording is illustrated if Fig. 3 showing the Till $3484 \AA$ line for different delays with respect to the laser pulse. The laser fluency and ambient nitrogen pressure are $10 \mathrm{Jcm}^{-2}$ and 0.1 Torr, respectively. We observe, that TiII $3484 \AA$ line emission starts with a large broadened and shifted profile indicating the initial high electron density.

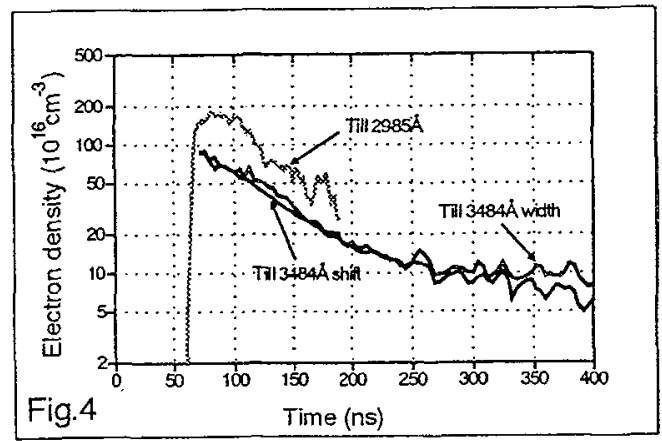

Then, in the recombining phase, the electron density diminishes and width and shift of the spectral line decrease.

Fig. 4 gives an example of the temporal evolution of electron density deduced from Stark broadening of TiIII $2985 \AA$ and from Stark broadening and shifting of TiII $3484 \AA$. A quite good agreement is obtained between values deduced from shift and width of Till $3484 \AA$ while electron density values deduced from Till $2985 \AA$ broadening are roughly two times higher. This may be due to self absorption of the Till $2985 \AA$ line or to the plasma inhomogeneity. We remember that the observed signal is an average value over a plasma layer of $0.1 \mathrm{~mm}$ thickness. Fig. 4 shows that the electron density increases rapidly after a delay of $60 \mathrm{~ns}$ with respect to the laser pulse.

After reaching its maximum value the electron
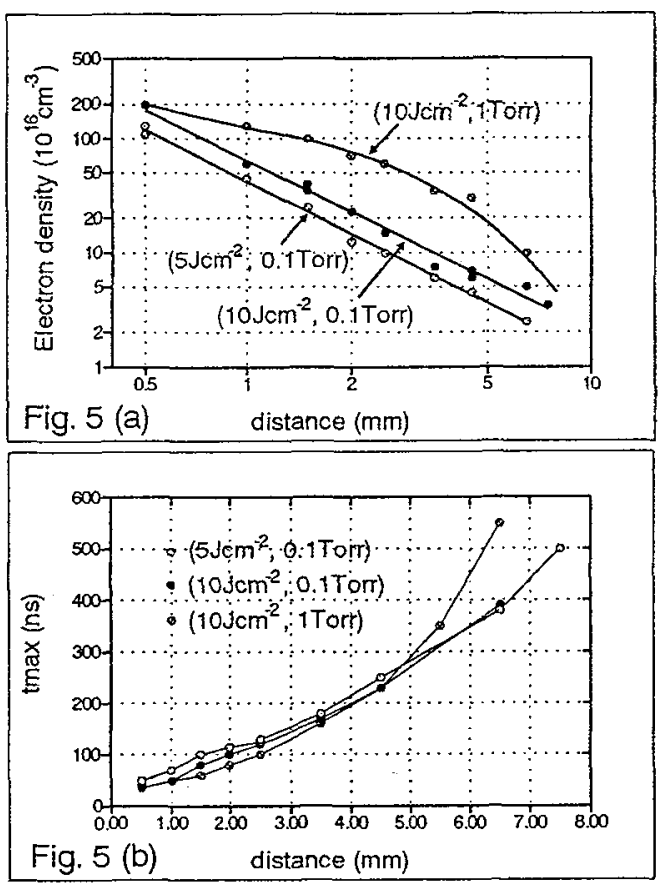
density decreases quasi exponentially.

In Fig. 5 we present the maximum values of electron density (a) and the corresponding laser delays (b) as a function of the distance from target for three different plasma conditions. First we note, that at 0.1 Torr ambient $\mathrm{N}_{2}$ pressure, the electron density varies with the distance from target as $d^{-3 / 2}$. When changing the laser fluency from 5 to $10 \mathrm{Jcm}^{-2}$, the electron density increases independent from the distance by a factor 1.5 . When changing the ambient nitrogen pressure from 0.1 to 1 Torr for a constant fluency of $10 \mathrm{Jcm}^{-2}$, the maximum electron density is unchanged near the surface $\left(2 \cdot 10^{18} \mathrm{~cm}^{-3}\right)$, while it is larger for distances up to $5 \mathrm{~mm}$. This is due to the confining effect of the ambient gas. At 1Torr the plasma expansion is reduced due to elastic collision with ambient gas atoms. Thus, at distances $\geq 8 \mathrm{~mm}$, the electron density at 1 Torr is lower than its value at 0.1 Torr. We see from Fig. $5 \mathrm{~b}$ that, near the targets surface, the plasma propagation velocity is roughly constant $\left(\cong 2 \cdot 10^{6} \mathrm{cms}^{-1}\right.$ ) when changing the laser energy or the ambient gas pressure. For 1Torr, the velocity decreases at higher distances due to collisions with ambient gas atoms.

\section{Conclusion}

The plasma formed by $\mathrm{XeCl}$ excimer laser vaporisation of a Ti-target in a low pressure nitrogen atmosphere can be characterised as follows: For laser fluencies from $5 . .10 \mathrm{~J} \mathrm{~cm}^{-2}$, primary ions Till and TiII are ejected from the metal surface. The velocity of plasma propagation perpendiculary to the surface is of $2 \cdot 10^{6} \mathrm{~cm} \mathrm{~s}^{-1}$. For ambient nitrogen pressures $\leq 0.1$ Torr, this velocity is conserved while at higher pressures the vapour plasma propagation is breaked due to elastic collisions. The expanding plasma cools rapidly and excitation or dissociation of the ambient gas is insignificant. Maximum values of electron density in the region near the surface are about $2 \cdot 10^{18} \mathrm{~cm}^{-3}$. The electrons come essentially from the metal vapour. The influence of ambient gas on the electron density is only indirect by its confining effect of the metal vapour plasma.

1 J. Kools, C. Nillesen, S. Brogersma, E. van de Riet, and J. Dielerman, J. Vac. Sci. Technol. A, 10, 1809 (1992)

2 I.N. Mihailescu, N. Chitica, L.C. Nistor, M. Propescu, V.S. Teodorescu, I. Ursu, A. Andrei, A. Barborica, A. Luches, M.L de Giorgi, A. Perrone, B. Dubreuil, and J. Hermann, J. Appl. Phys, 74, (1993)

3 J. Hermann, C. Boulmer-Leborgne, B. Dubreuil, and I.N. Mihailescu, J.Appl. Phys, 74, 3071 (1993)

4 J. Hermann, C. Boulmer-Leborgne, I.N.

Mihailescu, and B. Dubreuil, J.Appl. Phys, 74, 3071 (1993) 